\title{
Aspen Regrowth in Pastures of the Peace River Region
}

\section{W. L. PRINGLE, C. R. ELLIOTT, AND J. L. DOBB}

Highlight: Low-cost methods are required for converting wooded areas of Canada's Peace River region to productive pasture. Methods of circumventing the costly procedures of breaking the soil and removing roots preparatory to seeding were investigated. Various tillage implements (mouldboard plow, Rome disc-at 3 depths, rotovator, one-way disc, and tandem disc) were compared as to effectiveness for seedbed preparation. In addition, seed was both drilled and broadcast. Forage yields varied greatly, from an average of $1,184 \mathrm{lb} /$ acre on the plowed plots to $103 \mathrm{lb}$ on the check area. It was concluded that all methods tried tend to enhance tree establishment. Because of this, none of the methods tested would bring about an economically viable pasture.

It has long been advocated that livestock must be an integral part of the agriculture of the northern parts of British Columbia and Alberta. The grey wooded soils of the area dictate that development will be based on mixed farming rather than on a monoculture of cereal production in order to balance the poor crop years. British Columbia has 1.5 million acres reserved, of which 6,500 have been improved. Alberta has 60,000 acres with 17,500 improved. These tracts of land are strategically located with

\footnotetext{
Authors are forage ecologist and plant physiologist, Research Branch, Canada Agricult ure Research Station, Beaverlodge, Alberta, and district agriculturist, Dawson Creek, British Columbia.

The study is Northern Group Contribution No. NRG 72-6. The authors wish to acknowledge the cooperation of the B.C. Forest Service in allowing use of land on the Groundbirch community pasture.

Manuscript received May 6, 1972.
}

respect to farming areas and are bcing developed for livestock pastures. For the most part, the areas are heavily forested with aspen (Populus tremuloides Michx.). These trees vary in density from 250 to 2,000 stems per acre and from 2 to 8 inches $\mathrm{dbh}$ (diameter-breast-high). They have to be cleared from the land, using various mechanical methods (Friesen et al., 1965). The land is broken by using heavy machinery and then seeded.

\section{The Problem}

The main problem with pasture establishment after land clearing is the regrowth from suckers and roots of trees and brush. Any method of pasture preparation that allows the forest to easily regain its hold on the land is less than satisfactory. The methods used and the timing of clearing would appear to favor the regeneration of aspen. In addition to aspen, various species of willows (Salix spp.) as well as many other natives, such as rose (Rosa sp.), having the capability of vegetative propagation, attempt to repopulate the land.

Establishing a competitive crop of forage to help eliminate the brushy species has met with varying degrees of success. The problem, therefore, was to find the most satisfactory method assuring a reasonably good pasture for a minimum of time and expense that could be applied to large areas.

\section{Procedure}

An equipment trial was established on an area of 8 to 10 -inch $\mathrm{dbh}$ aspen, which would be classed as type 4 cover (Friesen et al., 1965). The trees were "walked down" by crawler tractor and piled in March, 1963. The soil was a sandy loam (Beryl series). The trial consisted of plots $50 \times 48 \mathrm{ft}$ laid out in three replicates with $30-\mathrm{ft}$ alleys used for turning areas. The machinery was pulled with a small crawler tractor. A 22-inch breaking plow was used, compared to three different depths of a 24-inch Rome disc, (D-deep, M-medium, S-shallow), a Howard rotovator, a one-way disc, and a tandem disc; a seeded check plot was established. Plots were split after cultivation on June 25, 1963 , and seed was drilled on one half using a double disc drill; on the other half 
Table 1. Number of plants on $60 \mathrm{ft}^{2}$ from drilled (D) and broadcast (B) seedings using various tillage methods.

\begin{tabular}{|c|c|c|c|c|c|c|c|c|c|c|c|c|c|c|c|c|}
\hline \multirow[b]{3}{*}{ Tillage methods } & \multicolumn{4}{|c|}{ Aspen } & \multicolumn{4}{|c|}{ Willow } & \multicolumn{4}{|c|}{ Rose } & \multicolumn{4}{|c|}{ Legumes } \\
\hline & \multicolumn{2}{|c|}{1964} & \multicolumn{2}{|c|}{1969} & \multicolumn{2}{|c|}{1964} & \multicolumn{2}{|c|}{1969} & \multicolumn{2}{|c|}{1964} & \multicolumn{2}{|c|}{1969} & \multicolumn{2}{|c|}{1964} & \multicolumn{2}{|c|}{1969} \\
\hline & $\mathrm{D}$ & $\mathrm{B}$ & $\mathrm{D}$ & $\mathrm{B}$ & $\mathrm{D}$ & B & $\bar{D}$ & B & $\mathrm{D}$ & $\mathrm{B}$ & $\mathrm{D}$ & $\mathrm{B}$ & $\mathrm{D}$ & B & $\mathrm{D}$ & B \\
\hline Mouldboard plow & 11 & 0 & 2 & 0 & 2 & 1 & 1 & 1 & 18 & 26 & 15 & 7 & 4 & 92 & 3 & 4 \\
\hline Rome decp & 2 & 4 & 1 & 2 & 6 & 6 & 2 & 0 & 26 & 16 & 11 & 7 & 28 & 92 & 4 & 8 \\
\hline Rome medium & 8 & 10 & 4 & 4 & 8 & 0 & 2 & 4 & 42 & 34 & 14 & 11 & 30 & 58 & 1 & 5 \\
\hline Rome shallow & 10 & 14 & 9 & 7 & 8 & 8 & 2 & 4 & 32 & 38 & 15 & 14 & 40 & 76 & 1 & 7 \\
\hline Rotovator & 2 & 2 & 2 & 3 & 5 & 4 & 2 & 1 & 22 & 14 & 19 & 20 & 30 & 132 & 1 & 1 \\
\hline One-way & 10 & 10 & 1 & 4 & 0 & 8 & 3 & 1 & 28 & 12 & 12 & 13 & 32 & 84 & 6 & 10 \\
\hline Tandem disc & 30 & 48 & 19 & 16 & 16 & 12 & 6 & 4 & 72 & 50 & 12 & 9 & 24 & 36 & 1 & 3 \\
\hline Check & 42 & 24 & 28 & 22 & 0 & 10 & 12 & 9 & 58 & 74 & 21 & 17 & 0 & 0 & 0 & 0 \\
\hline
\end{tabular}

seed was broadcast using a Century seeder. The seeding mix was Rambler alfalfa, Manchar bromegrass, Olds creeping red fescue, and Aurora alsike clover at $3,5,3$, and $2 \mathrm{lb} / \mathrm{acre}$, respectively. Seeds of legumes were appropriately inoculated. Plots were cut by hand to 2 inches, using a $9.6 \mathrm{ft}^{2}$ frame, 2 frames/sub-plot. Oven dry weight of forage was calculated each August for the years 1964, 1965, 1966, and 1969. Plant counts for legumes, poplar, willow, and rose were made in 1964 and 1969 by counting along a $20 \mathrm{x}$ 1 -ft line transect in each sub-plot. Cattle were allowed to graze the plots freely, along with the rest of the seeded pasture each fall during September.

\section{Results}

Establishment and Persistence of Seeded Species

Legume establishment, alfalfa and alsike clover, as shown in Table 1, was far greater for the broadcast plots than for those that were drilled. The greatest number were established in the rotovated plot. Perhaps this was because it was the smoothest seedbed. In all treatments the numbers of legume plants were reduced to very few per plot after 5 years. Alsike clover was nonexistent, and the surviving alfalfa plants were large and robust. The establishment of seeded grass was reflected in the yields as presented in Table 2. After 5 years the dominant grass was creeping red fescue.

\section{Yields}

A record of forage yields is shown in Table 2. Yield of dry matter was low during the year following seeding. In the second and third year the tandem disc plots and check gave significantly lower yields than the other treatments. By 1969, the check plot had filled in with 1 to $1 \frac{1}{2}$-inch diameter aspen, which impeded the growth of grazeable forage (Fig. 1). Drilling in the seed failed to promote higher herbage yields, compared to broadcast seeding. Wide fluctuation in yield from year to year reflects the precipitation for the growing season and represents a major difficulty in managing

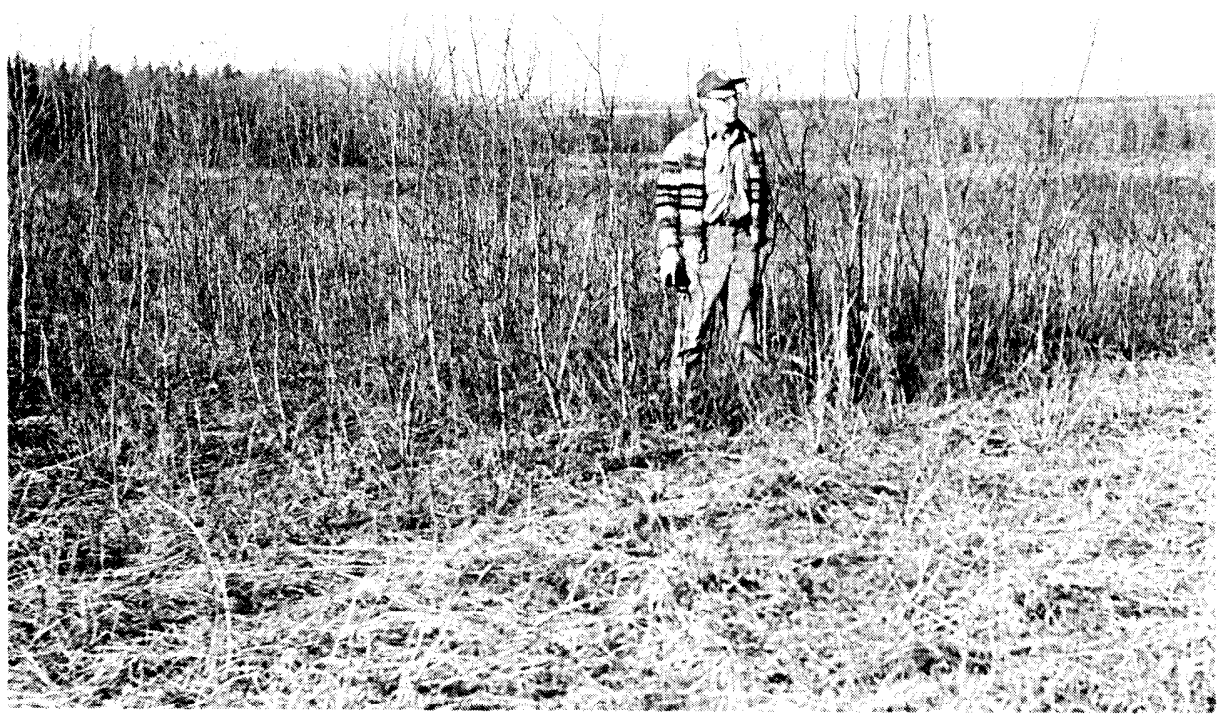

Fig. 1. Check plot showing aspen regrowth 6 years after tree removal and seeding to forages. The pathway in the foreground, which received considerable tillage before seeding, displays an excellent stand of alfalfa with no a spen regrowth.

these man-made ranges.

\section{Woody Regrowth}

A record of the major woody regrowth response is presented in Table 1 . The mouldboard treatment produced the lowest number of stems of aspen and willow. In 4 years a $50 \%$ reduction of woody regrowth was recorded for this treatment. The shearing action of a mouldboard blade cut the roots below the growing points and threw the severed crowns to the surface; thus the regrowth of the larger species such as aspen and willow was reduced. Rose roots occur in the surface layers and reproduction is by rhizomes. Plowing merely turned the layer over without disrupting growth.

The Rome disc treatments produced more woody regrowth than the plow. The number of regrowth stems decreased with the depth of discing. After 5 years the amount of aspen and willow remaining on the shallow-and medium-disced plots was greater than can be tolerated on a pasture. The Rome disc chopped and sliced on a shallow setting, thus splitting crowns of willow and aspen, which allowed for numerous regrowth possibilities. On a deep setting it threw the soil, which brought more of the roots to the surface.

The rotovator churned the surface layer to a depth of 4 to 6 inches, chopping up the finer roots into short lengths and kicking the larger roots to the surface. Unfortunately, it jumped over heavy stumps and larger willow crowns which provided regrowth. Rose rhizomes were cut up and incorporated on the fluffed-up layer, providing a ready source for re-establishment.

The one-way disc produced results similar to the shallow Rome disc. It appeared to be too light for efficient surface cultivation. Here again the chopping action helped to re-establish the rose. The tandem-disc proved far too light, as it did not penetrate well and did not cut the tree crowns. It too increased 
Table 2. Production (lb/acre, ovendry) of forage for 4 years, Groundbirch, B.C.

\begin{tabular}{lrrrrr}
\hline $\begin{array}{l}\text { Tillagc and } \\
\text { seeding methods }\end{array}$ & 1964 & 1965 & 1966 & 1969 & Avg \\
\hline Tillage methods & & & & & \\
$\quad$ Mouldboard plow & $529^{1}$ & $1.960 \mathrm{a}^{1}$ & $936 \mathrm{a}$ & $1,093 \mathrm{a}$ & $1,129 \mathrm{a}$ \\
Rome deep & 581 & $1,850 \mathrm{a}$ & $883 \mathrm{a}$ & $1,419 \mathrm{a}$ & $1,184 \mathrm{a}$ \\
$\quad$ Rome medium & 459 & $1,210 \mathrm{a}$ & $717 \mathrm{a}$ & $1,088 \mathrm{a}$ & $868 \mathrm{a}$ \\
Rome shallow & 537 & $1,440 \mathrm{a}$ & $552 \mathrm{a}$ & $1,242 \mathrm{a}$ & $944 \mathrm{a}$ \\
Rotovator & 601 & $1,190 \mathrm{a}$ & $583 \mathrm{a}$ & $950 \mathrm{a}$ & $826 \mathrm{ab}$ \\
One-way & 556 & $1,793 \mathrm{a}$ & $710 \mathrm{a}$ & $1,462 \mathrm{a}$ & $1,130 \mathrm{a}$ \\
Tandem disc & 200 & $350 \mathrm{~b}$ & $240 \mathrm{~b}$ & $1,025 \mathrm{a}$ & $455 \mathrm{bc}$ \\
Check & 175 & $49 \mathrm{~b}$ & $94 \mathrm{~b}$ & $96 \mathrm{~b}$ & $103 \mathrm{c}$ \\
X & 455 & 1,230 & 589 & 1,041 & 829 \\
S $\bar{x}$ & \pm 108 & \pm 298 & \pm 156 & \pm 212 & \pm 122 \\
C. V.\% & 41 & 42 & 46 & 35 & 25 \\
Sig. & NS & .05 & .05 & .05 & .05 \\
Seeding methods & & & & & \\
Drilled & 415 & 1,215 & 589 & 898 & 779 \\
Broadcast & 494 & 1,248 & 590 & 1,185 & 879 \\
Sig. ${ }^{2}$ & NS & NS & NS & NS & NS \\
\hline
\end{tabular}

${ }^{1}$ Means followed by the same letter within columns are not significantly different by Duncan's multiple range test at .05 level of probability.

${ }^{2} \mathrm{NS}=$ differences not significant; $.05=$ differences significant at the $5 \%$ level.

the rose regeneration.

Check plots were seeded but received no cultural treatment. Here the aspen and willow came back unhindered. Some reduction in stems of aspen and rose occurred over the 5 years owing to plant competition. The seeded species did not establish. Any forage yield taken consisted of native plants only.

\section{Discussion}

Zehngraff (1947), discussing the possibilities of managing aspen in the Lake States, showed that root suckers are produced by dormant buds on the horizontal roots near the surface. He found that winter-logged areas give abundant regeneration and summer-logged give nonsatisfactory regeneration. He reasoned that aspen roots are depleted of their stored food during the active growing season and suckers establishing late in the season are winter killed. On one of his areas where regeneration was poor, cross discing increased suckers from 750 to $2,400 /$ acre. On our check plots we had over 20,000 suckers/acre. Maini and Horton (1966) showed that temperature plays an important role in sucker initiation. Temperatures below $60^{\circ} \mathrm{F}$ or above $95^{\circ} \mathrm{F}$ inhibit sucker formation. They have shown that darkening the soil surface increases soil temperature. This insolation factor is cardinal for sucker stimulation. They speculated that diurnal temperature fluctuations play a favorable role in sucker initiation and tend to disagree with Farmer (1962) that aspen suckers appear on root systems only after the stems are cut, but not while trees are undamaged or vigorously growing.
Kozlowski (1960) stated that the total amount of seasonal height growth in aspen is correlated with the size of the terminal and is better related to environment of the previous season than to the current season.

By looking at the factors involved in stimulating and maintaining aspen, it becomes obvious that "land-clearing" dormant trees in the Peace River region enhances rather than limits subsequent sucker production. There is, of course, good reason for recommending winter land-clearing in that it disturbs less top soil and the heavy crawlers can move more easily over the frozen surface. The machinery trials reported here do indicate that certain implements and procedures are superior to others. Degree of cultivation has a bearing on forage establishment, as observed from the excellent stands of grass and legume occurring in the highly developed seedbeds on the pathways caused by turning the equipment. If we consider that even 1,400 suckers/acre as produced by the mouldboard treatment is the first step in a succession back to an aspen forest, then none of the methods used is satisfactory. The production of large scale pastures, therefore, cannot be successful using rough or once-over methods. The conclusion differs from that of Bailey (1972), who obtained satisfactory stands using a tandem disc and grain drill on newly cleared aspen parkland on a dark grey wooded soil. He followed this in one year with a herbicide treatment to help eliminate the brushy species. His total yield 2 years after seeding was between 1,000 and 1,300 pounds per acre of dry grass- legume forage.

On the grey wooded soil of the Peace River region, pastures will have to be gradually created by the use of annual grain cropping for 1 or 2 years to assure adequate brush removal and the crop used to partially defray the additional expense. This could be done along with an adequate aerial spray program prior to establishing a permanent grass-legume stand.

The production of usablc forage from the trials reported was disappointingly low with an average of 1,184 pounds/ acre. These studies were conducted without supplemental fertilizers. Subsequent investigations (unpublished data) on these soils have shown substantial yield responses to $\mathrm{N}$ and $\mathrm{S}$. In most years fertilizers can be profitably used to increase production.

Even without fertilizers production was 10 times that produced from the noncultivated check. Pastures as described have a limited life, and the cost of about $\$ 40 / a c r e$ must be borne by increased production. This would mean that at least 6 years of production are necessary to break even. Should other costs of the pasture, such as fences, bc included, then at least 10 years of good production would be required. Observation has shown that without additional spray programs or subsequent tillage the brush and trees will have dominated the stand in 10 years and production of forage for grazing will have been drastically reduced. It may then be concluded that there is no rapid, inexpensive cultural method to turn an aspen forest into a permancnt productive pasture in the Peace River area.

\section{Literature Cited}

Bailey, A. W. 1972. Forage and woody sprout establishment on cleared, unbroken land in Central Alberta. J. Range Manage. 25:119-122.

Farmer, R. E. 1962. Aspen root sucker formation and apical dominance. Forest Science $8: 403-410$.

Friesen, H. A., M. Aaston, W. G. Corns, J. L. Dobb and A. Johnston. 1965. Brush control in Western Canada. Canada Dep. Agr. Pub. 1240.

Maini, J. S., and K. W. Horton. 1966. Vegetative propagation of Populus spp. 1. Influence of temperature on formation and initial growth of aspen suckers. Can. J. Bot. 44:1183-1188.

Kozlowski, T. T. 1960. Photosynthesis, climate, and tree growth. The Ronald Press Co. New York, pp. 149-164.

Zehngraff, P. J. 1947. Possibilities of managing aspen in the Lake States. Lake States Forest Exp. Sta. Michigan. Rep. No. 21. 